\title{
Superconducting Fault Current Limiter for the Electric Power System
}

\author{
M. MAJKA* AND J. KOZAK \\ Electrotechnical Institute, M. Pożaryskiego 28, 04-703 Warsaw, Poland
}

\begin{abstract}
Superconducting fault current limiters are the most attractive devices for the power network, they can be used to limit the short current in electrical network. The operation of a superconducting fault current limiter is based on the sudden transition from the superconducting state to the normal state by exceeding the critical current $I_{c}$ of the material. This transition one takes a very short time, so fast that we are able to limit the first current peak to a threshold value which does not exceed three to five times the rated current. This paper presents the design, the calculated electrical parameters and tests of the medium voltage class superconducting fault current limiter prototypes made in Electrotechnical Institute. The constructed coreless superconducting fault current limiter consists of three windings: ones made of SF12050 tape and a parallel connected primary copper winding. All windings are inductively coupled and intended to work in liquid nitrogen.
\end{abstract}

DOI: 10.12693/APhysPolA.130.581

PACS/topics: 85.25.-j

\section{Introduction}

An electric short-circuit fault can damage equipment at the location of fault, and the resulting large fault currents can cause highly dynamic and thermal stresses in all electric grid components. Growth in the generation of electric power and an increased interconnection of the network leads to higher fault current levels. The principle of the superconducting fault current limiter (SFCL) is simple. During normal operation the system operates without any limitations because the impedance of the SFCL is essentially zero. However, during a fault when the fault current reaches many times the rated value, the superconducting element reverts rapidly to its normal state. The increased impedance limits the fault current to the desired level [1]. SFCLs react very rapidly by limiting the first, the most dangerous, surge current during a current fault condition, thus protecting the devices of the electric power network from the dynamic effects of current faults. The SFCL responds before the first cycle peak and provides effective means to limit excessive fault currents to safe levels without the disadvantages of conventional fault current mitigation methods. Present researches on fault current limiters focus on resistive type [2] and inductive type [3-11]. The drawback of the concept of inductive limiter with shielded core was insertion of a finite impedance in the line even during normal operation, and the large size and weight of the iron core $[7,10]$. The presented solution of a coreless construction reduces the weight of the device and the size of the primary copper winding and the voltage on the limiter during the normal operation is negligible.

\section{The design of the SFCL}

The limiter was designed to work in a $15 \mathrm{kV}$ power system. A constructed inductive type superconducting fault

\footnotetext{
*corresponding author; e-mail: m.majka@iel.waw.pl
}

current limiter is presented in Figs. 1 and 2. The main parameters of SFCL are presented in Table I, electrical schematic of the limiter is presented in Fig. 1.


Fig. 1. Design of the SFCL.

The limiter has two primary windings and six shorted secondary windings. The copper winding was wound onto an external bobbin and the superconducting windings on an internal bobbin. The primary winding, placed on the external bobbin, is made of a copper wire. The second primary winding is made of a $2 \mathrm{G}$ superconducting tape. The primary winding made of $2 \mathrm{G}$ tape is connected in parallel with the copper primary winding. The secondary HTS winding was shorted and made of a $2 \mathrm{G}$ superconducting tape. The primary and secondary superconducting windings were divided into twelve pancake coils. The length of HTS tape in one coil was $19 \mathrm{~m}$. The coils of the primary HTS windings were connected in series. All windings are magnetically coupled. The magnetic coupling between the $2 \mathrm{G}$ tape windings in the inner bobbin is greater than the magnetic coupling be- 


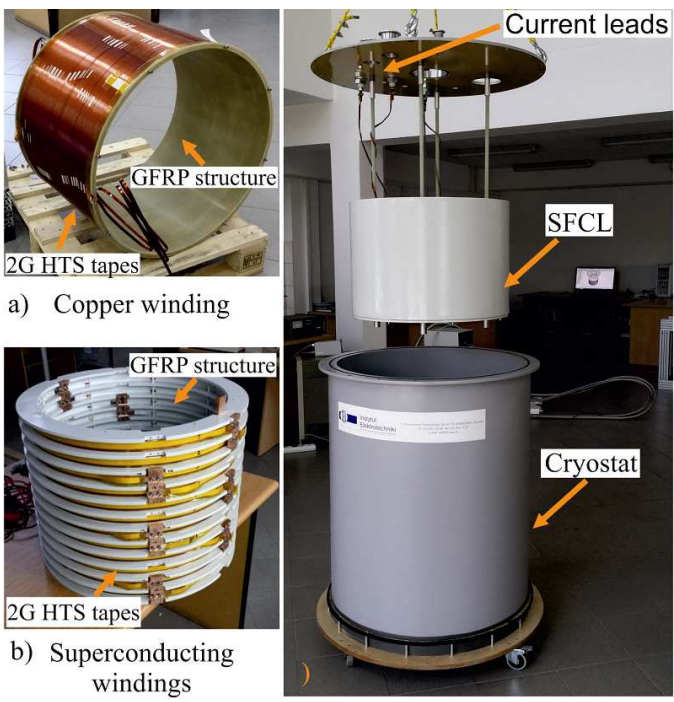

Fig. 2. Coreless inductive superconducting fault current limiter with winding made of SuperPower SF12050 second generation superconducting tape.

tween the $2 \mathrm{G}$ tape winding and the copper winding in the outer bobbin. The coupling coefficient between primary HTS and secondary HTS windings is 0.97 and between primary copper winding and secondary HTS winding is about 0.52 . The primary copper winding has 185 turns. The primary superconducting windings have 12 turns each and are connected in series. The secondary superconducting windings consist of two shorted superconducting windings, each with 12 turns. Both the primary and the secondary superconducting windings are wound onto a single bobbin in such a way that their turns are positioned one on top of the other, which provides a very good magnetic coupling between the windings and this, in turn, reduces the voltage during the SFCL's performance in nominal conditions.

The limiter was placed in a cryostat with an external vacuum insulation and cooled in a liquid nitrogen bath (Fig. 2). The cryostat of the limiter was made of glass fiber reinforced polymer (GFRP). Heat transfer in a cryostat was reduced thanks to a double wall which separates physical contact between the inside and outside of the container by creating a vacuum between the double walls. The cryostat was equipped with four copper current leads (Figs. 1,2). The current leads for $140 \mathrm{~A}$ nominal current were made of copper.

The primary copper winding has been wound using a $1.8 \times 7.5$ insulated copper wire. The superconducting winding has been wound using the SF12050 superconducting tape with $2 \mu \mathrm{m}$ silver layer and a resistance of HTS tape $0.104 \Omega / \mathrm{m}$ in resistive state at $77.4 \mathrm{~K}$. The primary and secondary superconducting windings are of the same length and have the same number of turns. The superconducting tape was insulated with $0.025 \mathrm{~mm}$ thick polyimide film with a $0.040 \mathrm{~mm}$ silicone adhesive during the winding process.
TABLE I

Parameters of SFCL.

\begin{tabular}{ll|c}
\hline \hline \multicolumn{1}{c|}{ Parameter } & Value \\
\hline nominal voltage & $U_{N}$ & $15 \mathrm{kV}$ \\
nominal current & $I_{N}$ & $140 \mathrm{~A}$ \\
voltage on the limiter $I_{N}$ & $U_{\text {SCFL }}$ & $<1 \mathrm{~V}$ \\
prospective peak current & $i_{\text {peak }}$ & $40 \mathrm{kA}$ \\
first peak limit & $i_{p}$ & $4.7 \mathrm{kA}$ \\
limitation time & $t_{\text {lim }}$ & $160 \mathrm{~ms}$ \\
operating temperature & $T$ & $77.4 \mathrm{~K}$ \\
cryostat hight & $H$ & $1 \mathrm{~m}$ \\
copper winding diameter & I.D. & $0.578 \mathrm{~m}$ \\
HTS windings diameter & I.D. & $0.506 \mathrm{~m}$ \\
number of copper turns & $n_{C u}$ & 216 \\
number of primary HTS turns & $n_{\mathrm{HTS} \mathrm{I}}$ & 144 \\
number of secondary HTS turns & $n_{\mathrm{HTS} \text { II }}$ & 144 \\
length of copper winding wire & $l_{\mathrm{Cu}}$ & $393 \mathrm{~m}$ \\
length of primary HTS winding wire & $l_{\mathrm{HTS} \mathrm{I}}$ & $229 \mathrm{~m}$ \\
length of secondary HTS winding wire & $l_{\mathrm{HTS} \text { II }}$ & $229 \mathrm{~m}$
\end{tabular}

\section{Numerical model of the SFCL}

The numerical model of the limiter was developed in the "Transient Magnetic" FEM-circuit Flux2D software. The geometry of the actual model of the limiter was substituted with a simplified axially symmetric geometry (Fig. 3). The outer circuit of the numerical model is presented in Fig. 4. The thermal issues which occur in the windings of the limiter are included in the user subroutine written in Fortran. According to this procedure, in every step in the calculations the temperature of the limiter's winding is determined using the energy balance, based on the present value of the current flowing through the limiter's windings. The energy balance equation takes into account the transition of the heat from the limiter windings to the liquid nitrogen. After determining the current temperature of the winding, the resistance of the winding is calculated on the basis of experimentally determined $R(I, T)$ relation for the SF12050 superconducting tape.

Simulations were performed for model of limiter whose parameters are presented in Table I. Thanks to the performed simulations, courses of a fault current in the circuit with and without the limiter were obtained (Fig. 5), as well as the changes of resistance and temperature of individual limiter windings during the limitation of the fault current (Fig. 6).

In the stand-by state, i.e. the first $40 \mathrm{~ms}$ of calculations, the superconducting windings of the limiter are in the superconducting state and a nominal current of $140 \mathrm{~A}$ flows through the limiter. The voltage value in all models of the limiter is lower than $1 \mathrm{~V}$, which results from a minor leakage reactance.

During a short-circuit lasting from $0.040 \mathrm{~s}$ to $0.200 \mathrm{~s}$, a fault current flows through the limiter. The peak value of the current in the shorted circuit $i_{p}=40 \mathrm{kA}$ was lim- 
ited to $3.5 \mathrm{kA}$ (Fig. 5). The course of the fault current causes the HTS windings to heat up very rapidly. The temperature of the windings increases from an initial temperature of $77.4 \mathrm{~K}$ to a maximum temperature $T_{\max }$ which is reached at the moment of switching off of the short-circuit (Fig. 6c). The performed simulation shows that the temperature of the superconducting windings increases much faster than the temperature of the copper windings, and that the maximum temperature of the limiter's superconducting windings at the moment of a short-circuit occurrence would not exceed $200 \mathrm{~K}$. Due to a substantial increase of the temperature of the limiter's HTS windings, the short circuit must be switched off by a conventional circuit breaker before the temperature of the HTS winding reaches the maximum value.
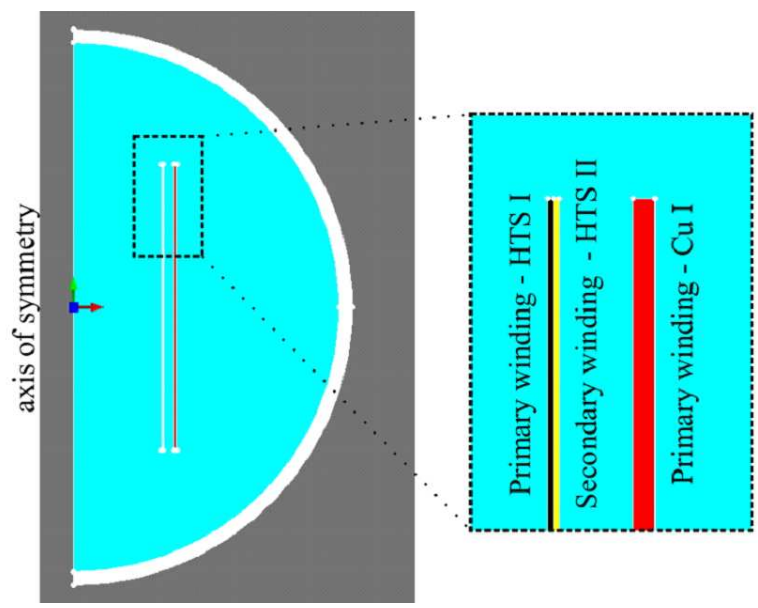

Fig. 3. Simplified geometry of numerical model in Flux2D.



Fig. 4. Electric circuit of numerical model of SFCL in Flux2D.

\section{Experimental tests}

The fault-current test was performed in Switchgear Testing Laboratory of Electrotechnical Institute in Warsaw. The test circuit (Fig. 7) consists of a 2.5 GVA shortcircuit generator, a master breaker $\mathrm{MB}$, a making switch $\mathrm{MS}$, power transformers $\mathrm{PT}$, reactors $\mathrm{L}$, resistors $\mathrm{R}$ and equipment for voltage and current measurements.

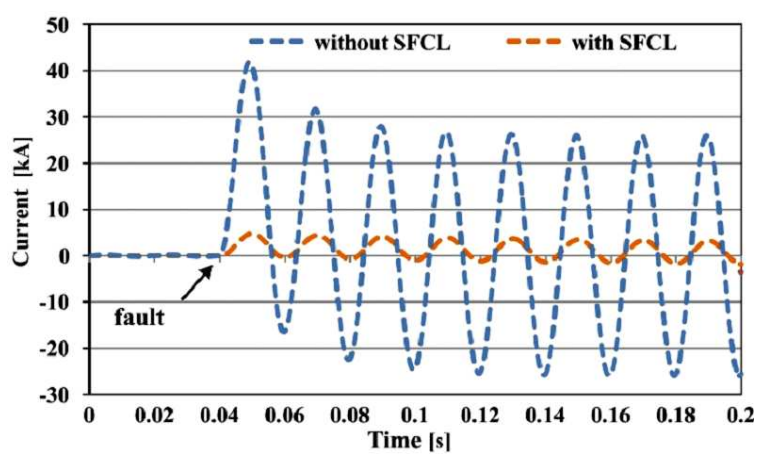

Fig. 5. Current wave forms in the circuit with and without SFCL.
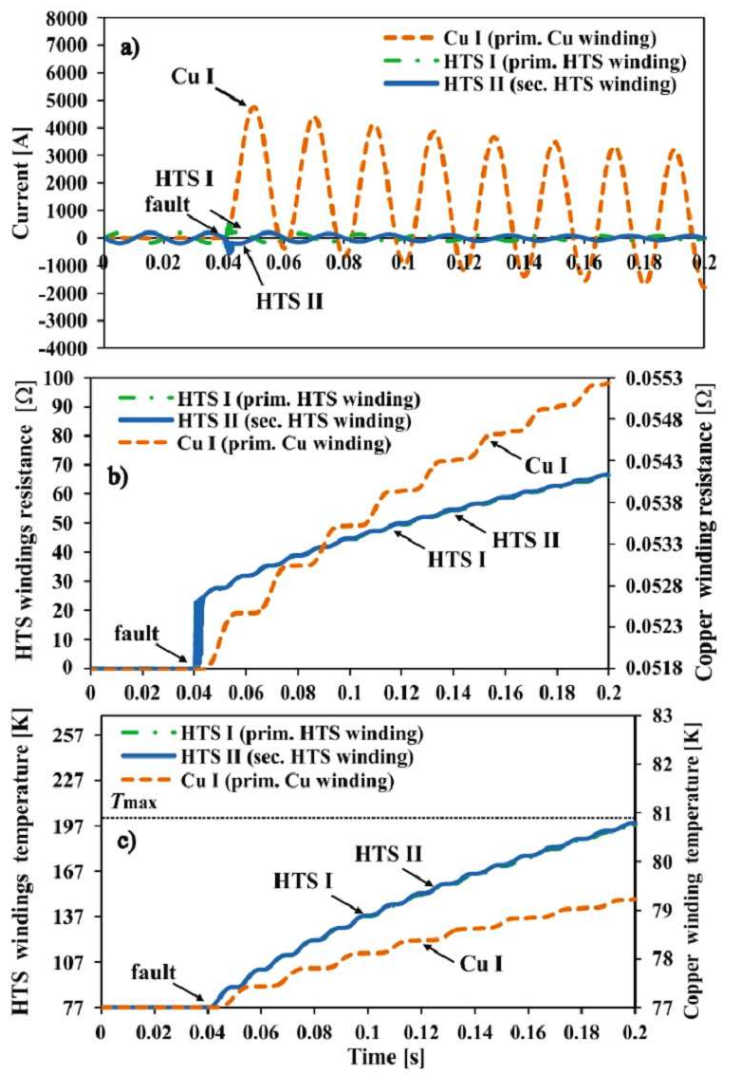

Fig. 6. Numerical model - current wave forms in the windings of the limiter (a), the changes of resistance (b) and temperature of individual limiter windings (c) during the limitation of the fault current (graphs for HTS I and HTS II windings overlap).

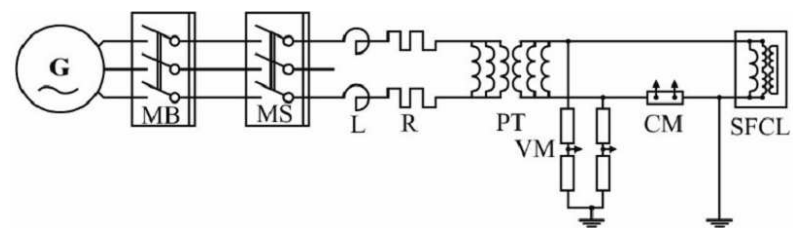

Fig. 7. Scheme of laboratory test circuit. 


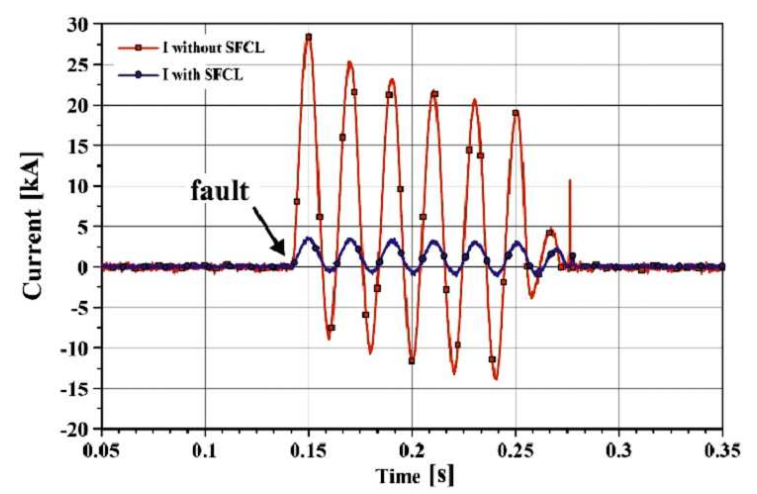

Fig. 8. Comparison of prospective and limited current courses, the first the most dangerous peak is limited eight times.

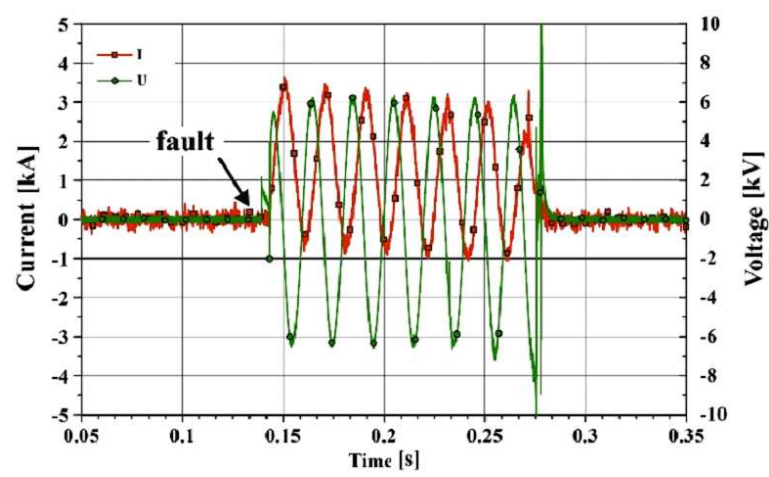

Fig. 9. Limited current course and voltage across the SFCL during the fault.

The aim of the power tests in the presented circuit was to measure and compare the prospective and limited current. Before the tests fault current limiter was cooled down using about $500 \mathrm{l}$ of liquid nitrogen. The duration of a short-circuit was $120 \mathrm{~ms}$.

The experimental results are presented in Figs. 8 and 9. The prospective current (first half) in the circuit $30 \mathrm{kA}$ has been limited eight times to $3.5 \mathrm{kA}$ by the superconducting fault current limiter. During fault the RMS voltage across the SFCL was $4.24 \mathrm{kV}$.

\section{Conclusion}

The constructed coreless superconducting fault current limiter effectively limit the peak value of the fault current from $30 \mathrm{kA}$ to $3.4 \mathrm{kA}$ within $120 \mathrm{~ms}$. The developed design in which the superconducting windings are wound simultaneously onto a single bobbin allows to obtain a very high coupling factor between the windings and minimize the leakage reactance of the limiter, which minimizes the voltage in the limiter in the stand-by state. The use of a connection in parallel of a copper coil and a superconducting coil in the primary winding protects the short circuit from opening in case when the superconducting tape is damaged. The fault current limiting capability of a limiter is determined mostly by the impedance of the copper winding coupled in parallel with the primary superconducting winding.

\section{References}

[1] S.S. Kalsi, Applications of High Temperature Superconductors to Electric Power Equipment, IEEE Press, Wiley, Hoboken 2011.

[2] A. Morandi, Physica C 484, 242 (2013).

[3] A. Berger, M. Noe, A. Kudymow, IEEE Trans. Appl. Supercond. 21, 1315 (2011).

[4] M. Noe, A. Hobl, P. Tixador, L. Martini, B. Dutoit, IEEE Trans. Appl. Supercond. 22, 5600304 (2012).

[5] J. Kozak, M. Majka, S. Kozak, T. Janowski, IEEE Trans. Appl. Supercond. 23, 5600604 (2013).

[6] M. Majka, S. Kozak, Przeglad Elektrotechniczny 85, 183 (2009).

[7] J. Kozak, M. Majka, T. Janowski, S. Kozak, G. Wojtasiewicz, B. Kondratowicz-Kucewicz, IEEE Trans. Appl. Supercond. 21, 1303 (2011).

[8] O. Naeckel, M. Noe, IEEE Trans. Appl. Supercond. 23, 5602404 (2013).

[9] O. Naeckel, M. Noe, IEEE Trans. Appl. Supercond. 24, 5601605 (2014).

[10] H. Heydari, A.A. Abrishami, M.M. Bidgoli, IEEE Trans. Appl. Supercond. 23, 5604610 (2013).

[11] J. Kozak, M. Majka, Przeglad Elektrotechniczny 03, 157 (2014). 